\title{
REVISTAMATĒRIA
}

\section{Desenvolvimento e avaliação de uma fonte DC de alta tensão para utilização em sistema de deposição de filmes finos por pulverização catódica}

\author{
Luís Gustavo Baptista Machuno ${ }^{1}$, Anderson Barbosa Lima ${ }^{1}$ \\ Rafael Rocha Buso ${ }^{1}$, Rubens Miguel Favarato Abdanur ${ }^{1}$ \\ Elidiane Cipriano Rangel ${ }^{2}$, Rogério Valentim Gelamo ${ }^{1}$
}

\author{
${ }^{1}$ Laboratório de Filmes Finos e Processos de Plasma - LFFPP/ICTE/UFTM- 38060280, Uberaba, MG, Brasil \\ ${ }^{2}$ Laboratório de Plasmas Tecnológicos - LaPTec - 18087-180, Sorocaba, SP, Brasil \\ *e-mail: rogelamo@gmail.com
}

\section{RESUMO}

O trabalho em questão está relacionado ao projeto e construção de uma fonte de alta tensão em corrente contínua utilizando materiais e dispositivos adquiridos no comércio local visando sua aplicação no processo de pulverização catódica. Essa técnica permite a deposição de filmes finos de metais, óxidos e nitretos sobre substratos sólidos. Como teste de funcionamento e aplicação da fonte DC, com a mesma instalada em canhão de pulverização em alto vácuo, filmes finos de diferentes espessuras de cobre, aço inoxidável 304 e tungstênio foram depositados e estudados. Análise de espessura, morfologia, e resistência elétrica e resistividade foram conduzidas. Filmes com resistividade elétrica dependente das espessuras foram obtidos. A fonte DC se mostrou confiável em operação e permite a deposição de uma infinidade de materiais nas mais diferentes espessuras sobre vários tipos de substratos.

Palavras-chave: fonte DC de alta tensão, filmes finos, sputtering, nanotecnologia, pulverização catódica, plasmas frios.

\section{ABSTRACT}

This work is related to the project and construction of a DC high voltage power supply using materials and electronic devices acquired in local stores and to be used in sputtering proposes. The technique allows the obtainment of several kinds of thin films such as metals, oxides, nitrides and others upon solid substrates. In order to perform a test, the DC power supply was installed in a high vacuum system, connecting the power supply directly in a magnetron sputtering gun. Thin films of copper, stainless steel 304 and tungsten of several thickness were deposited upon commercial glass slides. The film thickness, surface morphology, electric resistance, sheet resistance and resistivity were herein analyzed. The power supply shows a good reliability in operation and allows the deposition of several materials in various thickness and substrates.

Keywords: DC high voltage power supply, thin films, sputtering, nanotechnology, cold plasmas.

\section{INTRODUÇÃO}

Filmes finos são camadas formadas por determinado material, com espessura de poucos nanômetros até microns, que desempenham um papel crucial no desenvolvimento de diversos setores da indústria, tais como, microeletrônica, automotiva, aeroespacial, médica, optoeletrônica, química, embalagens e outras [1]. Em geral, são depositados ou crescidos por diversas técnicas sobre inúmeros tipos de substratos visando a obtenção de propriedades físicas ou químicas não apresentadas unicamente pelo substrato [2]. Como exemplo desta afirmação observa-se que filmes finos podem aumentar a dureza de superfícies [3], melhorar a proteção contra corrosão promovida por agentes químicos e ambientais [4], proteger contra a ação de radiação [5], diminuir o atrito de uma superfície [6], imitar o aspecto ótico de metais preciosos em bijuterias [7] filtrar comprimentos de onda específicos em dispositivos optoeletrônicos [8] ou até mesmo favorecer determinadas reações químicas em superfícies, propriedade necessária aos sensores de gases e líquidos [9,10].

$\mathrm{Na}$ indústria de alimentos, mais especificamente embalagens, filmes de metais são muito importantes 
para manter a qualidade dos alimentos, além disso, o emprego da metalização com filmes melhora o aspecto visual das embalagens[11]. A alternância de camadas de materiais isolantes, semicondutores e condutores em substratos semicondutores, são importantes para a construção de processadores, utilizados em equipamentos eletrônicos, que sem dúvida é uma aplicação importante para filmes finos [12] e utilizada por bilhões de pessoas em todo o mundo.

Uma das técnicas mais importantes nos setores científico e industrial para a deposição de filmes finos de diversos tipos de materiais é a chamada pulverização catódica (sputtering em inglês) [13]. O processo de pulverização catódica pode ser considerado como um fenômeno de colisões binárias entre íon incidente, com considerável energia cinética e o átomo de um material alvo, semelhante ao que ocorre num jogo de bilhar, ou seja, um problema de colisões mecânicas $[2,13]$. Diversos fenômenos podem ocorrer durante a interação do íon incidente e o material do alvo, mas o mais importante é aquele que leva à ejeção de átomos do alvo, sendo esse processo de ejeção chamado de sputtering.

Como a pulverização catódica é um processo realizado em vácuo, os átomos removidos do material alvo chegam ao substrato na forma atômica ou molecular [14]. Esses átomos se difundem pela superfície do substrato e a difusão depende da energia de ligação/interação com o substrato, da temperatura do substrato e de que material este é feito. Os átomos depositados começam o processo formando ilhas no substrato, que crescem e coalescem tocando umas nas outras. Dessa forma o filme fino vai se formando e à medida que mais material chega à superfície do substrato, a espessura do mesmo aumenta [13], formando assim um material homogêneo.

Para a construção de um sistema de pulverização catódica, muitos dispositivos são necessários, destacando-se o sistema de vácuo, composto pela câmara e as bombas de vácuo e a fonte de alta tensão DC para gerar os íons energéticos que irão colidir com o material alvo. Tipicamente o sistema de vácuo tem que propiciar pressões na faixa de $10^{-3}$ a $10^{-8}$ Torr [13]. Já as tensões necessárias no catodo, local a ser bombardeado pelos íons e portanto, onde é colocado o material alvo, vão de algumas centenas de Volts até alguns kVolts dependendo das dimensões dos alvos utilizados, bem como da condutividade elétrica dos mesmos [2].

O potencial elétrico a ser aplicado no material alvo é negativo com relação às paredes da câmara de vácuo, de modo a acelerar em sua direção os átomos positivamente carregados (íons), geralmente gases nobres, e assim, plasmas de descargas luminescentes são estabelecidos no interior da câmara [14]. Uma vez que as espécies contidas na descarga são de baixa energia, não geram efeitos térmicos apreciáveis e, portanto, todo o processo ocorre próximo da temperatura ambiente, sendo este processo considerado plasma frio [13]. Uma descrição mais detalhada do processo de plasma e de sua formação não é objeto do presente trabalho e pode ser encontrada em diversos trabalhos existentes na literatura [2,13,14].

Neste trabalho o projeto e montagem de uma fonte de alta tensão DC para utilização em um sistema de deposição de filmes finos por pulverização catódica será descrito. Características importantes do projeto da fonte DC e da câmara de vácuo serão mencionados, visando divulgar a técnica, que pode ser empregada em laboratórios de pesquisa e indústrias a custos não muito altos, já que os componentes da fonte são encontrados no mercado nacional. Serão mostrados resultados obtidos em nosso laboratório com o uso da técnica de pulverização catódica já em funcionamento, através da obtenção de filmes de cobre, aço inox 304 e tungstênio em quatro espessuras diferentes para cada material utilizado. Serão apresentados e discutidos resultados de morfologia das superfícies, rugosidade e caracterizações elétricas dos filmes obtidos com a técnica construída a fim de mostrar as possibilidades de uso da fonte DC construída na área de materiais, mais especificamente em pulverização catódica.

\section{MATERIAIS E MÉTODOS}

Na Figura 01 é apresentado o diagrama de blocos da fonte DC de alta tensão. A fonte é do tipo linear, onde a tensão alternada de entrada é aumentada ou diminuída através de um transformador, retificada por diodos e filtrada por capacitores. No diagrama existem duas fontes lineares como descritas. Uma principal de alta tensão, utilizada para a saída da fonte e outra, de baixa tensão, chamada de fonte auxiliar, utilizada para os circuitos de monitoramento e controle. O controle da tensão de saída é feito através de um varivolt de 1,5 kVA de potência máxima que permite variar a tensão de entrada do transformador de alta tensão de $0 \mathrm{~V}$ a 220 V rms e consequentemente variar a tensão de saída de $0 \mathrm{~V}$ a $1000 \mathrm{~V} \mathrm{rms}$, com corrente máxima de $1 \mathrm{~A}$.

Como um dos parâmetros de segurança, a etapa de alta tensão só é acionada através da chave geral, quando o varivolt é mantido em $0 \mathrm{~V}$, só a partir de então é que a tensão de saída pode ser elevada. Para a retificação de saída de alta tensão foi utilizada uma ponte de diodos para a retificação de onda completa. A ponte de diodos foi construída com 2 diodos em série em cada ramo para que a tensão reversa nos diodos utilizados (1N4007) não fosse alcançada. Após a retificação, tem-se o filtro capacitivo composto por 40 ca- 
pacitores de $68 \mu \mathrm{F} / 400 \mathrm{~V}$, associados de forma mista totalizando uma capacitância equivalente de $170 \mu \mathrm{F}$.

O bloco relativo ao circuito de amostragem de tensão e corrente mostrado na Figura 01, tem como propósito gerar um valor proporcional para essas grandezas dentro da faixa nominal de leitura da entrada analógica do microcontrolador (16F877A). Além de reduzir a tensão para um valor adequado, como outro parâmetro de segurança, foi necessário optoacoplar o sinal de tensão e de corrente que será enviado ao microcontrolador. Com o acoplamento óptico é possível isolar totalmente o circuito de alta tensão do circuito de monitoramento e controle. O acoplamento óptico garante maior segurança na operação da fonte através dos botões que estão ligados diretamente ao circuito de monitoramento e controle. O optoacoplador escolhido foi o IL300 por funcionar com o acoplamento óptico de sinais analógicos. O bloco relativo ao circuito de monitoramento e controle é a interface de acesso da fonte. Através da interface é possível monitorar os valores de tensão e corrente produzidas, ajustar o tempo de funcionamento e também emitir alertas visuais e sonoros relacionados à segurança durante a operação da fonte. $\mathrm{O}$ componente principal do circuito é o microcontrolador $16 \mathrm{~F} 877 \mathrm{~A}$ e a linguagem de programação adotada foi $\mathrm{C}++$ aplicada a microcontroladores, utilizando o compilador PCWHD da CCS.

Uma fonte de tensão DC auxiliar foi necessária para o funcionamento dos circuitos de monitoramento e controle. Na Figura 01 essa fonte é demonstrada através do bloco Fonte Auxiliar e tem tensões de saída retificadas de $15 \mathrm{~V}$ e $5 \mathrm{~V}$. Essas tensões foram obtidas através de retificadores de onda completa e filtros capacitivos. A estabilização de tensão foi feita através de circuitos integrados reguladores. Ainda como outro parâmetro de segurança a chave geral garante que os capacitores de filtro da etapa de alta tensão sejam descarregados através de resistores quando a fonte é desligada.

O conector de saída de alta tensão é um elemento de grande importância para o funcionamento adequado da fonte. É ele que faz a interface da fonte com o meio externo entregando a tensão para o canhão magnetron, sem perdas e com segurança. O material escolhido para a construção foi o PVC rígido devido à sua grande rigidez dielétrica.

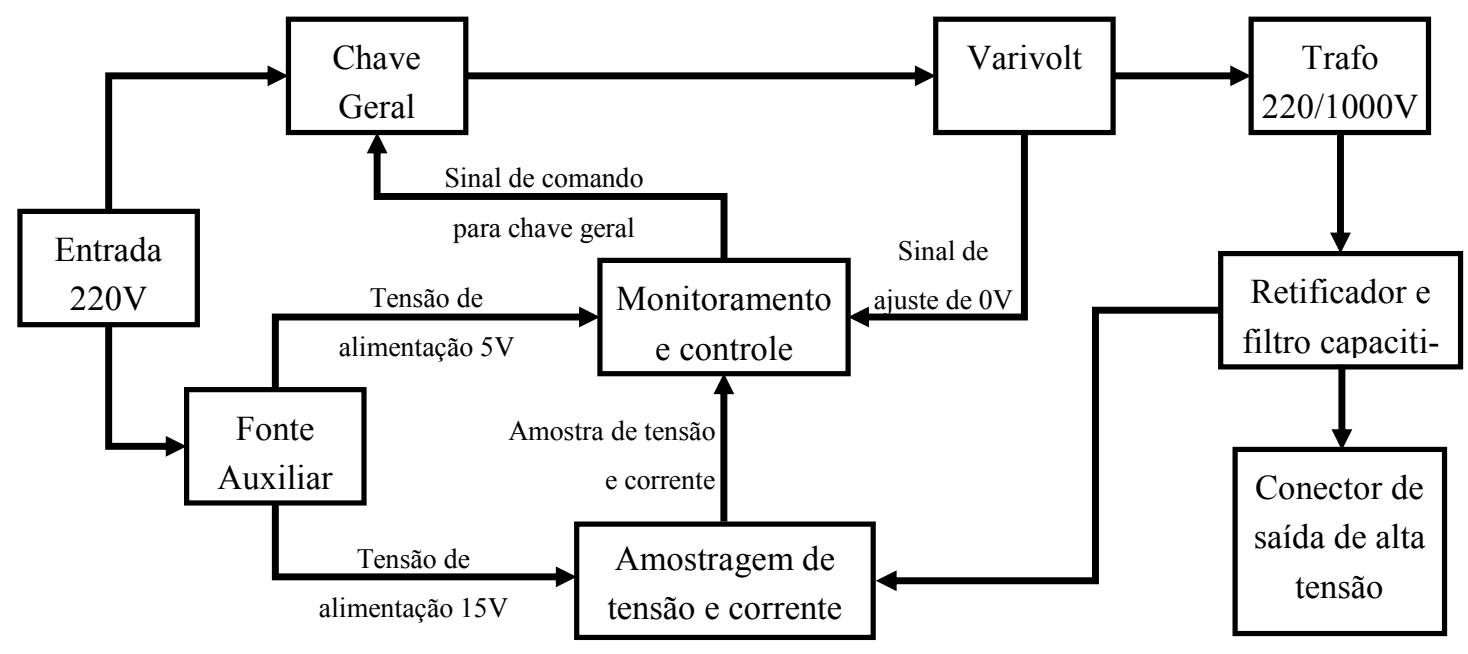

Figura 1: Diagrama de blocos da fonte DC de alta tensão construída para uso no sistema de pulverização catódica.

Vale ressaltar que a fonte DC de alta tensão foi inteiramente projetada e construída utilizando componentes obtidos no comércio nacional. Essa fonte tem características técnicas semelhantes às de fontes comerciais encontradas no comércio internacional, porém a um custo bem menor que o das fontes importadas. Outra característica importante foram os critérios de segurança que permitem o manuseio do equipamento sem riscos de descargas elétricas.

A fonte DC testada previamente em bancada de testes e mostrada na Figura 02 foi ligada ao sistema de vácuo, que é ilustrado na Figura 03. A câmara de vácuo construída em alumínio (diâmetro $30,0 \mathrm{~cm}$ e altura $35,0 \mathrm{~cm}$ ) possui conexões para vácuo e seus acessórios. No parte inferior (baseplate de aço inox $316 \mathrm{~L}$ ) encontra-se o medidor de pressão, que é um catodo frio, válvula para introdução de ar atmosférico, bomba de vácuo rotativa de palhetas com velocidade de $12 \mathrm{~m}^{3} / \mathrm{h}$ fabricado pela empresa Edwards e um conjunto composto de bomba de vácuo turbomolecular e bomba diafragma, com velocidade de bombeamento de $80 \mathrm{l} / \mathrm{s}$, fabricado pela empresa Agilent Technologies. 


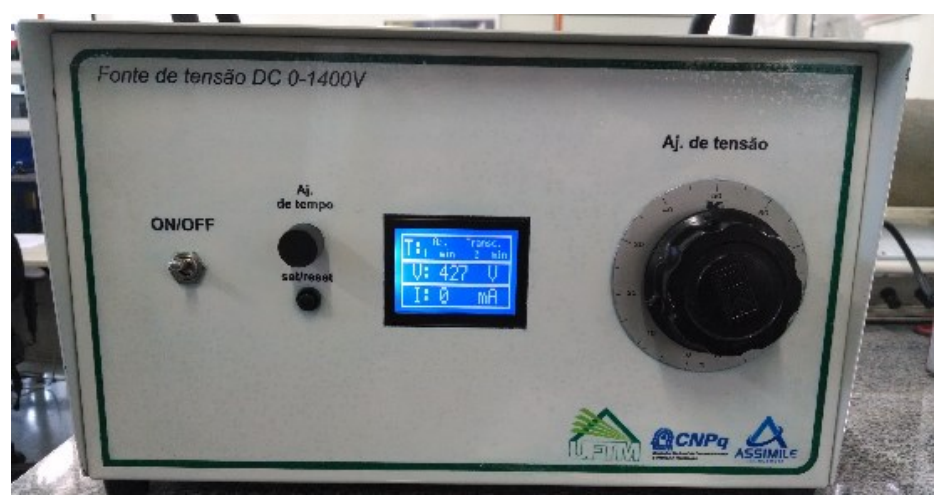

Figura 2: Foto da fonte DC em funcionamento no sistema de pulverização catódica.

Na parte superior da câmara se encontra a tampa removível que dá acesso ao seu interior. Na tampa se encontram também dois canhões magnetron para pulverização. O canhão nada mais é que um eletrodo construído para conectar eletricamente a fonte DC de alta tensão ao material alvo que se situa no interior da câmara de vácuo. Os alvos são chapas circulares, com diâmetro de 2 polegadas e espessura máxima de $5 \mathrm{~mm}$. Os alvos utilizados nesse trabalho foram de aço inoxidável 304 e cobre comercialmente adquiridos no comércio local e tungstênio de alta pureza (99,99 \%), adquirido da empresa Aldrich. Nas laterais da câmara encontra-se a janela de observação, feita de borosilicato com espessura de $7 \mathrm{~mm}$ e uma válvula de baixo fluxo para admissão de argônio industrial (pureza de 99,9 \%), gás utilizado nesse processo. Toda a câmara, bem como o polo positivo da fonte de alta tensão são aterrados, com exceção do eletrodo conectado ao canhão onde é colocado o alvo, que deve ser ligado ao polo negativo da fonte DC como mostra a Figura 03.
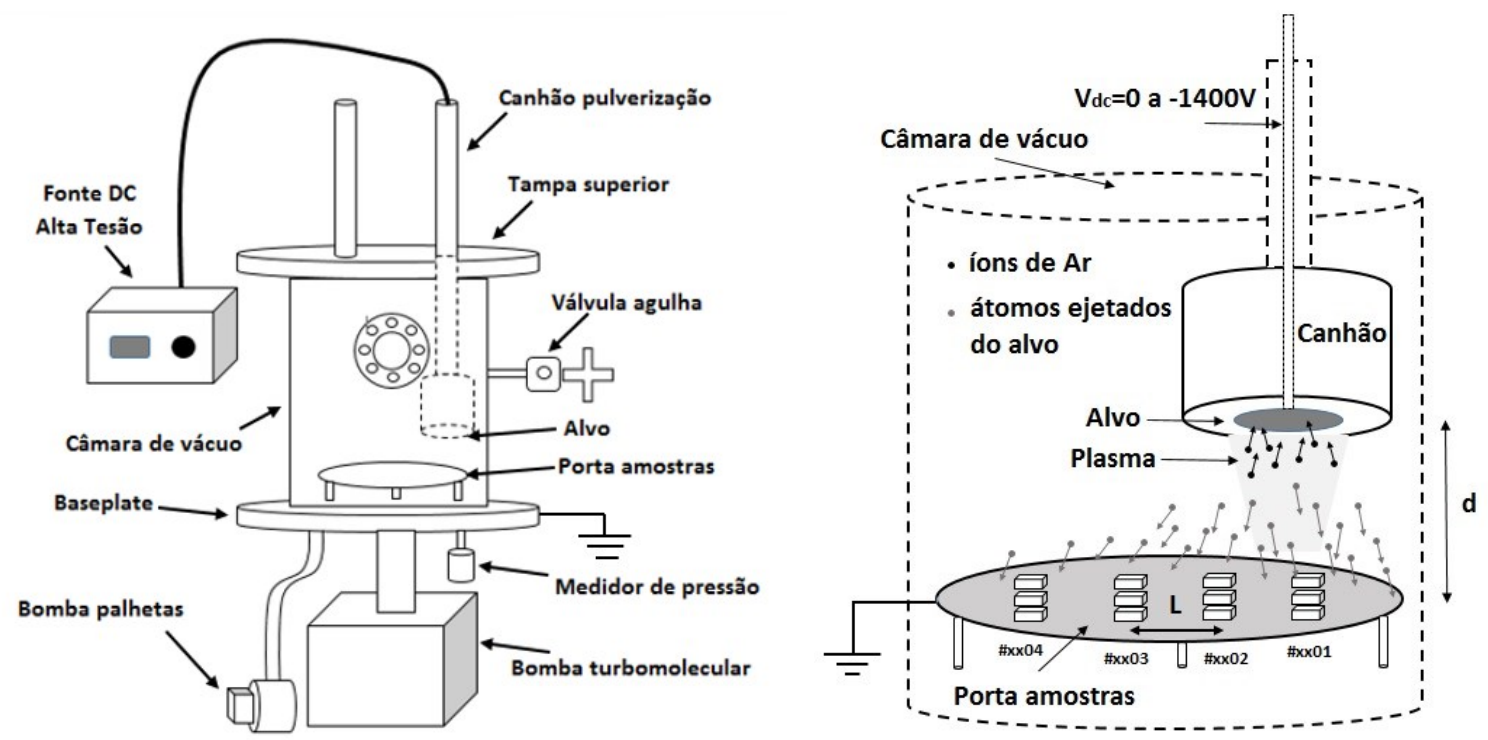

Figura 3: Representação ilustrativa do sistema de pulverização catódica projetado e montado para deposição de filmes finos diversos (à esquerda) e distribuição das amostras no interior da câmara de vácuo e as distâncias em relação ao canhão de pulverização e entre as amostras (à direita).

Ainda na Figura 03 é mostrada uma representação ilustrativa do processo de deposição dos filmes onde íons de argônio são acelerados pelo campo elétrico em direção ao alvo, descarga luminescente (plasma), e elétrons são gerados. Átomos do material alvo são ejetados com certa energia cinética e chegam ao porta amostras (substratos) e nas paredes da câmara de vácuo. Pelo processo de coalescência já descrito anteriormente o filme é formado sobre o substrato sólido. 
De modo a testar a fonte DC, filmes finos de cobre, aço inoxidável 304 e tungstênio foram depositados. Para cada material, doze pedaços de vidro (lâmina de microscópio cortadas no tamanho de 20.0 x 10.0 mm e previamente lavados com reagentes orgânicos) foram usados como substratos. A posição de cada substrato no porta amostras é ilustrada na Figura 03 (à direita), sendo a distância entre o canhão (com o material alvo a ser ejetado e então depositado nas amostras) e o porta amostras $\mathrm{d}=12.5 \mathrm{~cm}$ e a distância entre as amos$\operatorname{tras} \mathrm{L}=5.0 \mathrm{~cm}$.

A Tabela 01 indica as condições de deposição de cada material, ou seja, o potencial elétrico aplicado no eletrodo e consequentemente no alvo contendo o material a ser ejetado de modo a formar filme fino, a corrente elétrica e o tempo de deposição. Todos os materiais foram depositados à pressão de argônio de $1.0 \times 10^{-3}$ Torr

As espessuras dos filmes finos foram obtidas com perfilômetro Dektak D150 fabricado pela Veeco Co., instalado no Laboratório de Plasmas Tecnológicos da UNESP/Sorocaba. A morfologia de superfície foi obtida com microscópio de força atômica Shimadzu SPM9700 no modo contato e as rugosidades calculadas, a partir das imagens, com o software Shimadzu Manager V.4.01. Já as resistências elétricas foram obtidas utilizando eletrômetro Keithley 2635A usando o modo de quatro terminais, que permite a obtenção das resistividades de folha e resistividades dos filmes, conforme procedimento abaixo descrito. $\mathrm{O}$ eletrômetro e o microscópio de força atômica encontram-se instalados no Laboratório de Filmes Finos e Processos de Plasma da UFTM/Uberaba/MG.

Para o método de quatro terminais, corrente é introduzida e coletada no filme por meio de dois eletrodos, outros dois eletrodos paralelos e equidistantes medem o potencial elétrico nesses pontos [15]. O método é realizado com os eletrodos orientados horizontal e perpendicularmente de modo a obter uma média da resistência em ambas as direções na superfície do filme. $\mathrm{O}$ valor médio da resistência obtida nessas duas direções $R$ é então usado para o cálculo da resistência de folha $R s$, cuja unidade é $\Omega / \square$, através da equação (1). Conhecendo-se a espessura do filme $t$ é possível obter a resistividade dos filmes $\rho$ utilizando-se a equação (2). Dez medidas de espessura e dez medidas de resistência elétrica foram feitas em cada amostra de modo a efetuar os valores médios e seus desvios. Os desvios padrão da Resistência de folha e da Resistividade foram calculados à partir dos dados experimentais e utilizando também a equação geral de propagação de erros [16] e encontram-se nas equações 3 e 4 respectivamente.

$$
\begin{aligned}
& R s=\pi R / \ln 2 \\
& \rho=R s . t \\
& \Delta R s=\sqrt{(\partial R s / \partial R)^{2} \cdot(\Delta R)^{2}} \\
& \Delta \rho=\sqrt{\left[(\partial \rho / \partial R s)^{2} \cdot(\Delta R s)^{2}+\left((\partial \rho / \partial t)^{2} \cdot(\Delta t)^{2}\right)\right]}
\end{aligned}
$$

\section{RESULTADOS E DISCUSSÃO}

De modo a investigar o funcionamento e a eficiência da fonte DC bem como todo o sistema de vácuo, desenvolvidos e montados em nosso laboratório, três diferentes alvos (circular de 2 polegadas de diâmetros) foram utilizados para a obtenção de filmes finos. Foram utilizados como alvos para a pulverização catódica o cobre, o aço inoxidável 304 e o tungstênio.

Na Tabela 01 são apresentadas as condições de deposição dos filmes. Para cada material, três pedaços de vidro de $1.0 \mathrm{~cm} \times 1.0 \mathrm{~cm}$ foram dispostos no porta amostras (visando diferentes análises a serem posteriormente conduzidas) a cada $10.0 \mathrm{~cm}$ em relação ao centro do alvo, trata-se da distância L da Figura 03. Dessa forma os filmes foram rotulados pela sigla do material seguido do número que indica a distância em relação ao alvo, ou seja, a amostra rotulada por \#XX01 é aquela situada no ponto mais próximo do alvo e que portanto recebeu a maior quantidade de material, sendo a amostra mais espessa. Consequentemente a amostra rotulada por \#XX04 é a mais fina.

Já na Tabela 02 são apresentados os resultados de valores médios e desvios padrão de espessura, 
resistência elétrica, resistência de folha, resistividade e rugosidade para todos os filmes aqui estudados.

Tabela 1: Condições de deposição dos filmes finos de cobre, aço inoxidável e tungstênio.

\begin{tabular}{|l|c|c|c|}
\hline MATERIAL & TENSÃO (V) & CORRENTE (mA) & TEMPO DE DEPOSIÇÃO (min.) \\
\hline Cobre & 420 & 60 & 10 \\
\hline Aço Inoxidável 304 & 420 & 72 & 10 \\
\hline Tungstênio & 450 & 70 & 10 \\
\hline
\end{tabular}

Uma vez que o tempo de deposição foi o mesmo para todas as amostras, observa-se na Tabela 02 as diferenças de taxa de deposição dos diferentes materiais, muito embora o potencial elétrico aplicado no tungstênio tenha sido ligeiramente maior em comparação aos outros materiais utilizados, mas essa diferença não é apreciável. Os filmes de maiores espessuras medidas foram os de cobre seguidos pelo aço inox e tungstênio. Analisando o sputtering yield dos materiais utilizados, que representa o número de átomos ejetados do alvo por íon durante o processo de colisão [13], observa-se que o do cobre é maior que o do aço inoxidável, que por sua vez é maior que o do tungstênio. Para efeito de comparação para íons de argônio com energia de $2.0 \mathrm{keV}$ o sputtering yield é de aproximadamente 4.0 [17], 1.95 [18] e 1.3 [17] para o cobre, aço inoxidável 304 e tungstênio, respectivamente. Assim os valores de espessura apresentados na Tabela 02 seguem uma sequência coerente uma vez que obedecem a tendência do sputtering yield dos materiais utilizados. A posição das amostras em relação ao centro do canhão de pulverização também influenciou consideravelmente na espessura dos filmes. De fato, abaixo do canhão as espessuras são maiores uma vez que as espécies que chegam ao substrato apresentam uma dependência angular de acordo com Sigmund [19] e Wei et. al. [20].

Tabela 2: Valores médios e desvios padrão das grandezas analisadas nesse trabalho, para as amostras de cobre $(\mathrm{Cu})$, aço inoxidável 304 (AI) e tungstênio (W). A rugosidade média é representada na tabela por Ra.

\begin{tabular}{|c|c|c|c|c|c|}
\hline AMOSTRA & $\begin{array}{c}\text { ESPESSURA } \\
t(\mathrm{~nm})\end{array}$ & $\begin{array}{c}\text { RESISTÊNCIA } \\
R(\Omega)\end{array}$ & $\begin{array}{c}\text { RESISTÊNCIA } \\
\text { DE FOLHA RS } \\
(\Omega / \square)\end{array}$ & $\begin{array}{c}\text { RESISTIVIDADE } \\
\rho(\Omega . \mathrm{m})\end{array}$ & $\mathrm{Ra}(\mathrm{nm})$ \\
\hline $\mathrm{Cu} 01$ & $156.0 \pm 9.7$ & $0.078 \pm 0.002$ & $0.355 \pm 0.008$ & $5.5 \pm 0.4 \times 10^{-8}$ & 0.2 \\
\hline $\mathrm{Cu} 02$ & $138.7 \pm 8.0$ & $0.100 \pm 0.003$ & $0.454 \pm 0.016$ & $6.3 \pm 0.4 \times 10^{-8}$ & 0.6 \\
\hline $\mathrm{Cu} 03$ & $104.3 \pm 3.8$ & $0.592 \pm 0.034$ & $2.682 \pm 0.156$ & $2.8 \pm 0.2 \times 10^{-7}$ & 0.5 \\
\hline $\mathrm{Cu} 04$ & $21.3 \pm 1.9$ & $48.710 \pm 1.585$ & $220.660 \pm 7.181$ & $4.7 \pm 0.4 \times 10^{-6}$ & 0.3 \\
\hline AI01 & $70.0 \pm 2.7$ & $2.322 \pm 0.076$ & $10.520 \pm 0.343$ & $7.4 \pm 0.4 \times 10^{-7}$ & 1.2 \\
\hline AI02 & $56.8 \pm 3.9$ & $3.798 \pm 0.089$ & $17.207 \pm 0.402$ & $9.8 \pm 0.7 \times 10^{-7}$ & 0.7 \\
\hline AI03 & $47.0 \pm 3.8$ & $24.466 \pm 1.652$ & $110.833 \pm 7.483$ & $5.2 \pm 0.5 \times 10^{-6}$ & 0.5 \\
\hline AI04 & $26.3 \pm 2.0$ & $1039.730 \pm 130.859$ & $4710.042 \pm 588.250$ & $1.2 \pm 0.2 \times 10^{-4}$ & 0.4 \\
\hline W01 & $92.8 \pm 2.9$ & $23.515 \pm 0.731$ & $106.522 \pm 3.311$ & $9.9 \pm 0.4 \times 10^{-6}$ & 0.9 \\
\hline W02 & $52.7 \pm 3.5$ & $37.894 \pm 2.212$ & $171.663 \pm 10.021$ & $9.0 \pm 0.8 \times 10^{-6}$ & 1.2 \\
\hline W03 & $36.8 \pm 3.4$ & $173.362 \pm 8.371$ & $785.339 \pm 37.920$ & $2.9 \pm 0.3 \times 10^{-5}$ & 0.2 \\
\hline W04 & $26.9 \pm 3.0$ & $1814.429 \pm 113.045$ & $8219.478 \pm 512.083$ & $2.2 \pm 0.3 \times 10^{-4}$ & 1.2 \\
\hline
\end{tabular}

Com o aumento da espessura, observa-se na Figura 05 que devido ao processo de coalescência dos átomos na superfície, que as ilhas observadas na Figura 04 e visivelmente mais isoladas num primeiro estágio de formação dos filmes finos, crescem de modo a formar um material mais homogêneo com aumento dos domínios cristalinos, um material com cristalitos maiores é esperado nessa etapa do crescimento e as propriedades do material tendem para àquelas do material em volume.

Já a resistência elétrica, resistividade de folha e resistividade mostraram um comportamento similar para todos os materiais estudados, com diminuição de seu valor em função do aumento da espessura dos filmes, tendendo para valores constantes, conforme pode ser observado na Figura 06, onde são mostrados os valores de resistividade elétrica em função da espessura dos filmes, para os três materiais estudados nesse 
trabalho.
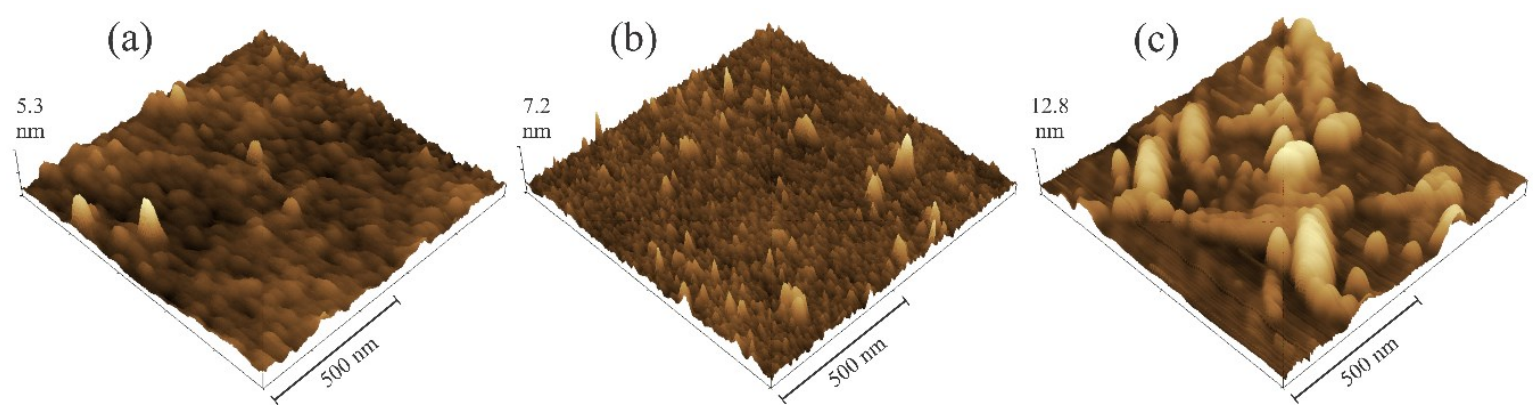

Figura 4: Morfologia de superfície obtida através de microscopia de força atômica dos filmes mais finos de (a) cobre, (b) aço inoxidável 304 e (c) tungstênio.
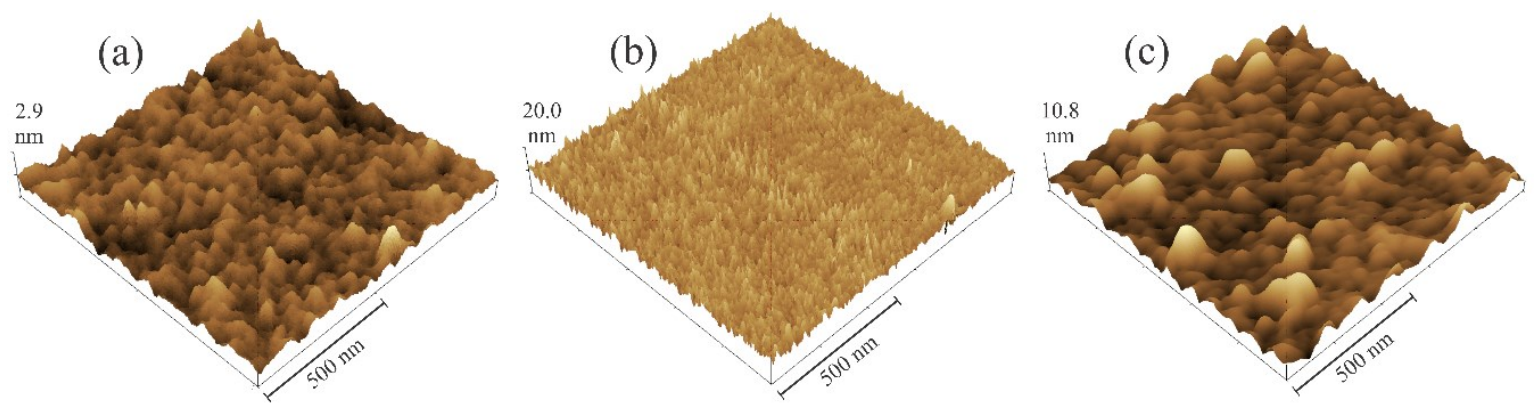

Figura 5: Morfologia de superfície obtida através de microscopia de força atômica dos filmes mais espessos de (a) cobre, (b) aço inoxidável 304 e (c) tungstênio.

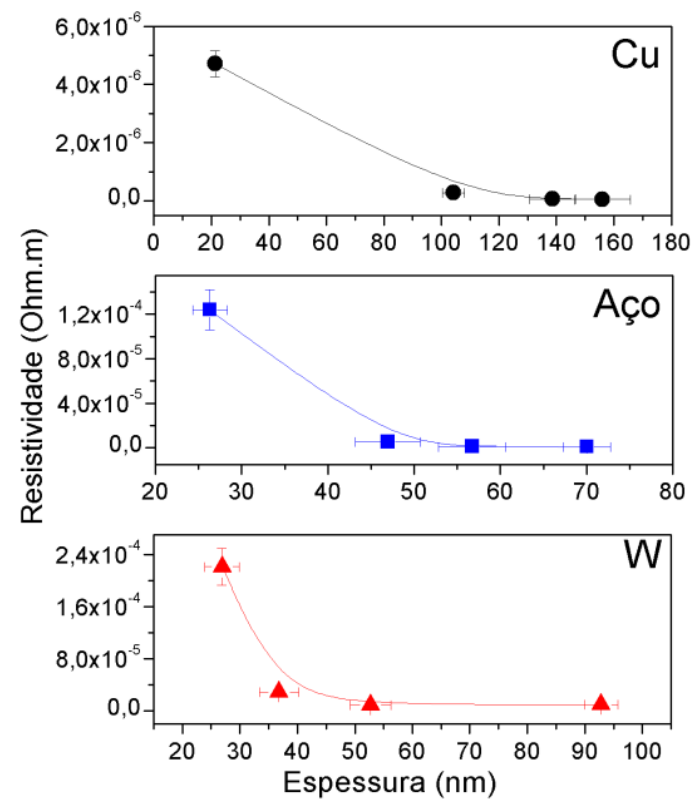

Figura 6: Resistividade em função da espessura para os três materiais estudados nesse trabalho. As linhas passando pelos pontos são apenas guias para os olhos. 
Dessa forma, as resistividades alcançam valores de $5.5 \pm 0.4 \times 10^{-8} \Omega . \mathrm{m}, \quad 7.4 \pm 0.4 \times 10^{-7} \Omega . \mathrm{m}$ e $9.9 \pm 0.4 \times 10^{-6} \Omega . m$ para o cobre, aço inoxidável e tungstênio, respectivamente. Na literatura valores de $1,7 \times 10^{-8} \Omega . \mathrm{m}, 7,2 \times 10^{-7} \Omega$.m e $5,3 \times 10^{-8} \Omega . \mathrm{m}$ são relatados para o cobre, aço inox e tungstênio [21] em volume (bulk), respectivamente. A diferença entre os valores obtidos e os encontrados na literatura podem estar relacionadas ao fato de que os materiais aqui estudados são filmes finos, enquanto que os citados na literatura são para materiais em volume. Outra possível causa é a cristalinidade que pode ser influenciada pela espessura, em geral filmes muito finos apresentam tamanho de grão cristalino menor que os observados em material em volume [22] devido ao processo de nucleação do filme. Nos filmes aqui estudados podemos também ter efeito de oxidação da superfície, tanto durante a deposição quanto após a exposição das amostras à atmosfera.

Nos filmes mais finos estudados observa-se que as resistividades aumentam consideravelmente para todos os materiais. Esse resultado pode ser devido a dois processos que ocorrem durante o crescimento dos filmes. Para filmes muito finos, como o processo de crescimento do filme no substrato é por coalescência [13], as ilhas de material começam a se formar e podem não se tocar com as ilhas vizinhas, conforme se observa nas imagens de AFM da Figura 04. Dessa forma, com o menor número de conexões entre as ilhas a resistência para a passagem de corrente elétrica aumenta, resultando em filmes muito resistivos. Outro efeito que corrobora para os altos valores de resistividade nos filmes mais finos é a presença de óxido nativo. Como os filmes de maior resistividade são muito finos, a camada de óxido formada pela exposição desses materiais ao ar atmosférico é considerável em relação às camadas não oxidadas e como esses óxidos são em geral materiais semicondutores ou isolantes, a resistividade medida tem um valor consideravelmente maior em comparação com os filmes mais espessos aqui estudados.

\section{CONCLUSÕES}

Uma fonte de alta tensão operando em corrente contínua foi projetada e construída visando sua utilização no processo de pulverização catódica. Os custos de sua construção bem como os dos equipamentos necessários para sua montagem não são elevados e não requerem mais do que usualmente existe num laboratório de pesquisa em materiais.

O sistema de vácuo utilizado se mostrou eficiente e eficaz para a realização de vácuo na região entre $10^{-7}$ e $10^{-2}$ Torr. Neste trabalho, foram depositados e estudados filmes de cobre, aço inoxidável 304 e tungstênio. Filmes com resistividade dependente da espessura foram obtidos, com valores próximos daqueles observados na literatura para os filmes depositados nas maiores espessuras. A técnica de pulverização permitirá em nosso grupo de pesquisa a obtenção de uma grande quantidade de diferentes materiais a serem empregados nas áreas de sensores químicos e biológicos, área de embalagens alimentícias, pesquisa em eletrônica, recobrimento de superfícies para fins de proteção e decoração e muitas outras aplicações.

\section{BIBLIOGRAFIA}

[1] OHRING, M., Engineering materials science, San Diego, Academic Press, Inc., 1995.

[2] SMITH, D. L. Thin-film - principles na practice, 1 ed., New York, McGraw-Hill, 1995.

[3] GELAMO R. V., DURRANT, S. F., et al, "Helium ion irradiation of polymer films deposited from TMSAr plasmas", Plasma Processes and Polymers, v. 4, n. 4, pp. 489-496, May 2007.

[4] ARMAN, S.Y., OMIDVAR, H., et al., "Evaluation of nanostructured S-doped TiO2 thin films and their photoelectrochemical application as photoanode for corrosion protection of 304 stainless steel", Surface and Coatings Technology, v. 251, pp. 162-169, July 2014.

[5] CHEN, S., MA, H., et al., "Smart VO2 thin film for protection of sensitive infrared detectors from strong laser radiation", Sensor and Actuators A: Physical, v. 115, pp. 28-31, Sept. 2004.

[6] RAMALIGAN, S., "Tribological characteristics of thin films and applications of thin film technology for friction and wear reduction”, Thin Solis Film, v. 118, pp. 335-349, Aug. 1984.

[7] KOPACZ, U., RIEDL, R., "Deposition of decorative gold-colored thin-films by ion-assisted pvd processes", Zeitschrift fur metallkunde, v. 83, n. 7, pp. 492-499, July 1992.

[8] BLOEMER, M., SCAROLA, M., "Metallic optical filters with low sheets resistence", In: 16th Conference on Solar Optical Material, pp. 50-57, Denver, July 1999.

[9] GELAMO, R.V., ROUXINOL, C., et al., "Low-temperature gas and pressure sensor based on multi-wall carbon nanotubes decorated with Ti nanoparticles", Chemical Physics Letters, v. 482, pp. 302-306, Oct. 2009. 
[10] GELAMO, R.V., ROUXINOL, C., et al., "Gas and pressure sensors based on multi-wall carbon nanotubes: study of sensing mechanisms”, Sensor Letters, v. 8, n. 3, pp. 488-492, Jan. 2010.

[11] GAVITT, I.F. "Vacuum Coating Applications for Snack Food Packaging", In: Proceedings of the 36th Annual Technical Conference of the Society of Vacuum Coaters, pp254-258, 1993.

[12] ANDERSON, J.C. "Applications of thin films in microelectronics”, Thin Solid Films, v. 12, pp. 1-15, Sept. 1972.

[13] CHAPMAN, B. Glow discharge processes: sputtering and plasma etching, 1 ed., New York, John Wiley \& Sons, 1980.

[14] LIMA, E. C., GUARANY, C. A., ARAÚJO, E. B.“Construção de um sistema de pulverização catódica DC de baixo custo para deposição de filmes metálicos”, Revista Brasileira de Aplicações de Vácuo, v. 25, n. 4, pp 203-208, 2006.

[15] GIROTTO, E. M., SANTOS, I. A.“Medidas de resistividade elétrica DC em sólidos: como efetuá-las corretamente", Química Nova, v. 25, n. 4, pp 639-647, July 2002.

[16] VUOLO, J. H., Fundamentos da teoria de erros, 2 ed., São Paulo, Edgand Blücher, 1996.

[17] MATSUNAMI, N., YAMAMURA, Y., et al., "Energy dependence of the ion-induced sputtering yields of monatomic solids", Atomic Data and Nuclear Data Tables, v. 31, n. 1, pp. 1-80, July 1984.

[18] SEEFELD, H.V., SCHMIDL, H., BEHRISCH, R., et al., "Sputtering yields of 1 to 20kev light ions on stainless steel”, Journal of Nuclear Materials, v. 63, pp. 215-221, Dec. 1976.

[19] SIGMUND, P., “Theory of Sputtering. I. Sputtering Yiel of Amorphous and Polycrystalline Targets ”, Physical Review, v. 184, n. 2, pp. 383-416, Aug. 1969.

[20] WEI, Q., LI, K-D., LIAN, J., et al., “Angular Dependence of Sputtering Yield of Amorphous and Polycrystalline Materials”, Journal of Physics D: Applied Physics, v. 41, n. 17, pp. 1-4, Aug. 2008.

[21] CALLISTER Jr., W.D., RETHWISCH, D. G., Ciência e engenharia de materiais - uma introdução, 8ed., Rio de Janeiro, LTC editora, 2015.

[22] MIYAZAKI, S., FU, Y. Q., et al, Thin film shape memory alloys - fundamentals and device applications, 1 ed., New York, Cambridge University Press, 2009. 